\title{
Daya Tetas Telur Burung Puyuh (Coturnix coturnix japonica) Pada Suhu Dan Indeks Bentuk Telur Berbeda
}

\section{(Hatchability of Japanese quail eggs (Coturnix coturnix japonica)} on different temperatures and egg shape indexes)

\author{
Budi Indarsih, Moh.Hasil Tamzil, I Nyoman Sukartha Jaya, \\ Ni Ketut Dewi Haryani dan Muhamad Albi \\ Laboratorium Produksi Ternak Unggas Fakultas Peternakan Universitas Mataram, \\ Jl. Majapahit No. 62 Mataram. 83125. \\ Email : budiindarsih@unram.ac.id
}

Diterima : 03 Mei 2021/Disetujui : 02 Juni 2021

\begin{abstract}
ABSTRAK
Penelitian ini bertujuan untuk mengetahui daya tetas telur burung puyuh (Coturnix coturnix japonica) pada suhu dan indeks telur yang berbeda. Penelitian dilaksanakan di Laboratorium Ternak Unggas Fakultas Peternakan Universitas Mataram. Rancangan percobaan yang digunakan adalah Rancangan Acak Lengkap Faktorial (suhu dan indeks bentuk telur). Telur sebanyak 480 butir dibagi 4 perlakuan yaitu telur ditetaskan dengan 2 suhu berbeda yaitu suhu tinggi $39^{\circ} \mathrm{C}$ dan suhu rendah $37^{\circ} \mathrm{C}$ dengan 2 indek berbeda yaitu indeks bentuk telur $>78 \%$ (bulat) dan $<78 \%$ (lonjong) dengan 3 ulangan setiap perlakuan sehingga setiap ulangan menggunakan 40 butir telur. Hasil penelitian membuktikan bahwa suhu dan indeks bentuk telur dan interaksinya tidak berpengaruh $(\mathrm{P}>0,05)$ terhadap performan penetasan.
\end{abstract}

Kata kunci: kematian embrio, daya tetas, bulat, lonjong

\begin{abstract}
This study was conducted to determine the hatchability of Japanese quail eggs (Coturnix coturnix japonica) at different temperatures and egg shape indexes. This work was carried out at the Poultry Laboratory, Faculty of Animal Science, University of Mataram. The experimental layout used was a completely randomized design with factorial arrangements. A total of 480 eggs were divided into 4 treatments, namely 2 different temperatures (high: $39^{\circ} \mathrm{C}$ and low $37^{\circ} \mathrm{C}$ ) and 2 different egg shape indexes, namely egg index $>78 \%$ (round) and $<78 \%$ (oval) with 3 replications of each treatment using 40 eggs. The other incubation conditions were identical for all groups. The results showed that temperature and egg index as well as interaction had no effect $(\mathrm{P}>0.05)$ on embryonic mortality, hatchability and the quality of dayold quail.
\end{abstract}

Keywords: embryonic mortality, hatchability, round, oval 


\section{PENDAHULUAN}

Suhu merupakan salah satu faktor lingkungan yang secara langsung menstimulir perkembangan embrio selama proses penetasan. Untuk itu diperlukan suatu ketepatan dalam menentukan suhu yang digunakan. Parkhurst dan Moutney (1998) menyatakan bahwa telur unggas akan banyak menetas jika berada pada suhu antara $94-104^{\circ} \mathrm{F}\left(36-40^{\circ} \mathrm{C}\right)$ dan embrio tidak toleran terhadap perubahan suhu yang drastis. Adanya kisaran suhu yang cukup lebar $\left(10^{\circ} \mathrm{C}\right.$ atau $\left.4^{\circ} \mathrm{C}\right)$ disebabkan oleh karena adanya perbedaan karakteristik dari masingmasing jenis unggas dan salah satu faktor yang dominan adalah bobot telur dan ketebalan kerabang. Menurut Givisiez et al. (2000) meningkatnya $1^{\circ} \mathrm{C}\left(38,8^{\circ} \mathrm{C}\right)$ di atas suhu inkubasi optimum $\left(37,8^{\circ} \mathrm{C}\right)$ mulai hari ke-13 inkubasi menyebabkan penurunan secara signifikan daya tetas telur broiler, sedangkan efek tersebut tidak teramati ketika suhu diturunkan pada $1^{\circ} \mathrm{C}\left(36,8^{\circ} \mathrm{C}\right)$. Telur puyuh memiliki karakteristik ukuran telur yang kecil dengan ketebalan kerabang yang relatif tipis. Oleh karena itu dibutuhkan suhu yang spesifik yang dapat memacu peningkatan daya tetas. Selama ini standar suhu yang digunakan dalam penetasan telur puyuh mengacu pada standar yang digunakan pada penetasan telur ayam, oleh karena itu perlu dilakukan pengamatan terhadap suhu yang tepat pada penetasan puyuh untuk meningkatkan daya tetas.

Suhu inkubasi atau suhu spesifik embrio merupakan faktor paling penting yang akan mempengaruhi hasil tetasan serta kualitas day old quail (DOQ). Faktor - faktor yang berpengaruh terhadap temperatur embrio adalah produksi panas embrio, suhu udara di dalam inkubator periode setter dan hatcher, kelembaban udara serta kecepatan aliran udara (Meijerhof, 2009). Suhu yang ideal biasanya memungkinkan mencapai daya tetas dan bobot tetas maksimum. Dua hal penting dalam penetasan yang perlu diperhatikan dan dapat mempengaruhi perkembangan embrio yaitu suhu dan $\mathrm{O}_{2}$ (Meijerhof, 2009). Sampai saat ini suhu inkubasi telur unggas liar masih bervariasi dari $33^{\circ} \mathrm{C}$ sampai $39^{\circ} \mathrm{C}$, sedangkan kisaran $37^{\circ} \mathrm{C}$ sampai $38^{\circ} \mathrm{C}$ merupakan suhu optimal inkubasi untuk ternak unggas lokal atau domestikasi (Visschedijk, 1991). Suhu inkubasi telur puyuh masih bervariasi dari $37,5^{\circ} \mathrm{C}$ hingga $40^{\circ} \mathrm{C}$ (Romao et al., 2009a). Pengaturan suhu mesin tetas untuk penetasan telur puyuh adalah $37^{\circ} \mathrm{C}$ dan $38^{\circ} \mathrm{C}$. Secara umum, suhu inkubasi yang tinggi $\left(38^{\circ} \mathrm{C}, 39^{\circ} \mathrm{C}, 40^{\circ} \mathrm{C}\right.$, dan $\left.41^{\circ} \mathrm{C}\right)$ akan mengakibatkan bobot tetas menurun, sedangkan pada suhu inkubasi yang lebih rendah $\left(34^{\circ} \mathrm{C}\right.$, $35^{\circ} \mathrm{C}, \quad 36^{\circ} \mathrm{C}, \quad$ dan $37^{\circ} \mathrm{C}$ ) akan menghasilkan daya tetas dan bobot 
tetas yang rendah (Romao, et al., 2009b). Pengaruh kelembaban (Romao et al., 2009b), menunjukkan bahwa kelembaban rendah $(36.05 \pm 6.06 \%)$ dengan suhu $37,5^{\circ} \mathrm{C}$ menghasilkan daya tetas tertinggi (79\%) dibanding kelembaban $\quad 52.25 \pm 4.99 \%$ ) dan kelembaban tinggi $(76.50 \pm 4.44 \%)$. Dengan kata lain, suhu tinggi dan kelembaban tinggi sangat kritis bagi penetasan puyuh. Faktor eksternal ke dua yang penting menentukan daya tetas adalah indeks bentuk telur. Penelitian Kul dan Seker (2005) menunjukkan bahwa indek bentuk telur puyuh $79,0 \%$ dan $74,0 \%$ mempunyai pengaruh terhadap daya tetas dan setiap kenaikan $1 \%$ indeks bentuk telur menurunkan daya hidup 1,6\%. Indeks bentuk telur juga menentukan transfer panas.

Oleh karena itu penelitian ini dilakukan untuk mengetahui daya tetas terbaik telur burung puyuh pada suhu dan indeks bentuk telur yang tepat.

\section{MATERI DAN METODE}

Penelitian ini dilaksanakan pada bulan September sampai November 2020, bertempat di Laboratorium Ternak Unggas Fakultas Peternakan Universitas Mataram. Sejumlah 480 butir telur puyuh fertil dibagi menjadi 4 perlakuan dengan rancangan faktorial ( 2 suhu: tinggi $39^{\circ} \mathrm{C}$ dan rendah $37^{\circ} \mathrm{C}$ ) dan 2 indeks bentuk telur (bulat dengan indeks $>78 \%$ dan lonjong dengan indeks $<78 \%$ ). Kondisi inkubator sama untuk semua kelompok perlakuan.

\section{Penetasan pada puyuh}

Telur fertil yang ditentukan indeks bentuknya dimasukkan telur ke mesin tetas otomatis sederhana terbuat dari triplek dengan kapasitas 400 butir. Posisi telur diletakkan dengan bagian tumpul di atas dan telur dibiarkan pada posisinya dari hari 1 sampai ke 3 tanpa dibalik. Meneropong (candling) telur dengan lilin atau senter untuk mengetahui telur yang fertil pada hari ke 4 . Setelah peneropongan kemudian telur dibalik 3 kali setiap hari pada pagi, siang dan sore $(06: 00 ; 14.00 ; 22.00$ WITA). Pembalikan dihentikan pada hari ke 15 dengan posisi telur horizontal dengan kelembaban 60$70 \%$. Telur yang menetas pada hari ke 17 segera dikeluarkan dan telur yang masih pipping ditunggu hingga menetas hari ke-20 kemudian menilai DOQ (day old quail) atau puyuh umur sehari) yang sudah menetas untuk diseleksi dan dikelompokan normal dan abnormal.

\section{Peubah yang diamati}

Parameter yang diamati dalam penelitian ini adalah sebagai berikut: Daya tetas dari telur yang ditetaskan = Jumlah DOQ menetas: Jumlah telur yang ditetaskan x $100 \%$

Daya tetas dari telur fertil $=$ Jumlah DOQ menetas: Jumlah telur fertil x $100 \%$ 
Kematian embrio awal $=$ (Jumlah kematian embrio awal: total telur fertil) $\mathrm{x}$ $100 \%$

Kematian embrio tengah $=$ (Jumlah kematian embrio tengah: total telur fertil) x $100 \%$

Kematian embrio akhir $=$ (Jumlah kematian embrio akhir : total telur fertil) x $100 \%$

\section{Analisa data}

Data yang diperoleh dianalisis menggunakan analisis sidik ragam (ANOVA) dari Rancangan Acak
Perbedaan rata-rata performan penetasan diuji lanjut dengan Tukey's test pada taraf $\mathrm{P}<0.05$ dan $\mathrm{P}<0.01$ dengan bantuan SAS versi 9.1 (2004)

\section{HASIL DAN PEMBAHASAN}

Hasil analisis data kematian embrio awal, kematian embrio tengah, kematian embrio akhir, daya tetas, dan kualitas tetas telur burung puyuh pada mesin tetas dengan suhu dan indeks bentuk telur yang berbeda dapat dilihat pada Tabel 1.

Lengkap (RAL) pola Faktorial.

Tabel 1. Kematian Embrio, Daya Tetas, dan Kualitas Tetas pada Mesin Tetas dengan Suhu dan Indeks Bentuk Telur Berbeda. (\%)

\begin{tabular}{lcccccc}
\hline & \multicolumn{3}{c}{ Kematian embrio } & \multicolumn{2}{c}{ Daya tetas } & $\begin{array}{c}\text { Kualitas } \\
\text { tetas }\end{array}$ \\
\cline { 2 - 7 } & Awal & Tengah & Akhir & Fertile & Total telur & \\
\hline Suhu & & & & & & \\
Rendah (R) & 6,6 & 8,3 & 19,1 & 66,1 & 56,3 & 83,0 \\
Tinggi (T) & 14,0 & 10,1 & 21,0 & 49,9 & 41,4 & 78,3 \\
SEM & 2,102 & 2,053 & 2,706 & 4,463 & 4,042 & 4,968 \\
Bentuk telur & & & & & & \\
Indeks Bulat (B) & 11,3 & 6,0 & 18,3 & 59,3 & 52,1 & 80,4 \\
Indeks Lonjong (L) & 4,6 & 3,5 & 8,5 & 56,7 & 45,6 & 81,0 \\
SEM & 2,102 & 2,053 & 2,696 & 4,463 & 4,042 & 4,968 \\
Interaksi & & & & & & \\
R x B (RB) & 7,5 & 6,4 & 19,4 & 66,7 & 58,3 & 84,7 \\
R x L (RL) & 5,6 & 10,1 & 18,7 & 65,5 & 54,2 & 81,4 \\
T x B (TB) & 15,0 & 5,7 & 17,3 & 52,0 & 45,8 & 76,1 \\
T x L (TL) & 13,0 & 14,4 & 24,7 & 47,9 & 36,9 & 80,6 \\
SEM & 2,102 & 2,053 & 2,696 & 4,463 & 4,042 & 4,968 \\
Faktor & & & Probability & & & \\
Suhu & $\mathrm{NS}$ & $\mathrm{NS}$ & $\mathrm{NS}$ & $\mathrm{NS}$ & $\mathrm{NS}$ & $\mathrm{NS}$ \\
Indeks bentuk telur & $\mathrm{NS}$ & $\mathrm{NS}$ & $\mathrm{NS}$ & $\mathrm{NS}$ & $\mathrm{NS}$ & $\mathrm{NS}$ \\
Interaksi & $\mathrm{NS}$ & $\mathrm{NS}$ & $\mathrm{NS}$ & $\mathrm{NS}$ & $\mathrm{NS}$ & $\mathrm{NS}$ \\
Suhu x indeks bentuk & $\mathrm{NS}$ & $\mathrm{NS}$ & $\mathrm{NS}$ & $\mathrm{NS}$ & $\mathrm{NS}$ & $\mathrm{NS}$ \\
telur & & & & & & \\
\hline
\end{tabular}

Keterangan: SEM -Standard Error of Mean 


\section{Kematian embrio}

Terdapat tiga kematian embrio yang umumnya di evaluasi dalam penetasan yaitu kematian embrio awal, tengah dan akhir. Hasil penelitian menunjukkan bahwa kematian embrio tidak dipengaruhi $(\mathrm{P}>0,05)$ oleh perbedaan suhu inkubator dan indeks bentuk telur (Tabel 1). Untuk semua periode pengamatan kematian, suhu incubator tinggi menyebabkan kematian embrio juga tinggi. Pengaruh bentuk telur, kematian embrio tidak terdapat perbedaan $(\mathrm{P}>0,05)$ untuk telur bentuk lonjong maupun bulat. Akan tetapi terdapat kecenderungan bahwa kematian embrio cenderung lebih tinggi untuk ketiga periode pengamatan terjadi pada telur bentuk bulat. Demikian juga bentuk telur, kematian embrio awal tidak dipengaruhi oleh bentuk telur $(\mathrm{P}>0,05)$ akan tetapi bentuk bulat cenderung mempunyai kematian embrio yang lebih tinggi dari pada telur bentuk lonjong. Tidak terdapat interaksi dua faktor suhu dan indeks bentuk telur. Hasil penelitian ini sama dengan hasil yang dilaporkan Soliman et al. (1994) bahwa kematian embrio selama periode awal (early embryonic mortality-EM) bervariasi dan tidak signifikan. Berbeda dengan penelitian Alasahan dan Copur (2016) pada ayam serta Aryee et al. (2020) pada puyuh bahwa bentuk telur mempengaruhi kematian embrio awal penetasan (Gambar 1). Penelitian ini memperoleh data bahwa bentuk telur lonjong menghasilkan kematian embrio awal $11.3 \%$ dan bentuk bulat $4.3 \%$, walaupun keduanya tidak berbeda $(\mathrm{P}>0.05)$. Hal yang sama pada kematian embrio tengah dan akhir. Menurut Aryee et al. (2020), ukuran telur menentukan parameter eksternal dan internal telur. Korelasi antara ukuran telur dan semua parameter telur adalah positif. Dengan demikian, dalam menguji operasional inkubator dengan berbagai treatmen, maka mengelompokkan telur berdasarkan ukuran adalah penting.

$$
\text { Soliman et al. }
$$

menunjukkan bahwa telur yang berhasil menetas atau pipping mengalami penurunan bobot telur lebih sedikit sampai umur 15 hari inkubasi daripada telur yang mati akhir penetasan (late embrionic motality-LM). Telur yang mengandung embrio mati awal (EM) menunjukkan penurunan bobot telur terbesar. Konsentrasi pori-pori pada ujung tumpul setiap telur paling besar pada telur yang menetas. Konsentrasi pori-pori di ekuator terbesar pada telur berhasil menetas dan paling sedikit pada telur embrio mati awal. Dengan kata lain bahwa kematian embrio terutama dipengaruhi oleh pori-pori kulit telur dan kondisi ketebalan kerabang. Faktor suhu sangat krusial karena embrio sangat sensitif terhadap suhu penetasan yang lebih rendah atau lebih tinggi. Suhu penetasan yang lebih rendah akan memperlambat dan semakin tinggi suhu inkubasi akan mempercepat pertumbuhan dan perkembangan embrio (Elsayed et al., 2009). Kematian 
embrio awal meningkat pada suhu rendah $\left(<35,5^{\circ} \mathrm{C}\right)$, sedangkan kematian embrionik menengah dan akhir meningkat pada suhu tinggi $\left(>36,5^{\circ} \mathrm{C}\right)$. Nakage et al. (2003) penelitiannya pada telur ayam hutan dengan beberapa kali penetasan dengan kondisi inkubasi hariannya sama dan menggunkan inkubator yang sama, melaporkan daya tetas lebih tinggi diperoleh dengan menggunakan suhu inkubasi antara $35,5^{\circ} \mathrm{C}$ dan $36,5^{\circ} \mathrm{C}$; suhu inkubasi berbanding terbalik dengan panjang (lama) inkubasi, dan bobot absolut maupun relatif dan ayam hutan tidak dipengaruhi oleh suhu inkubasi.

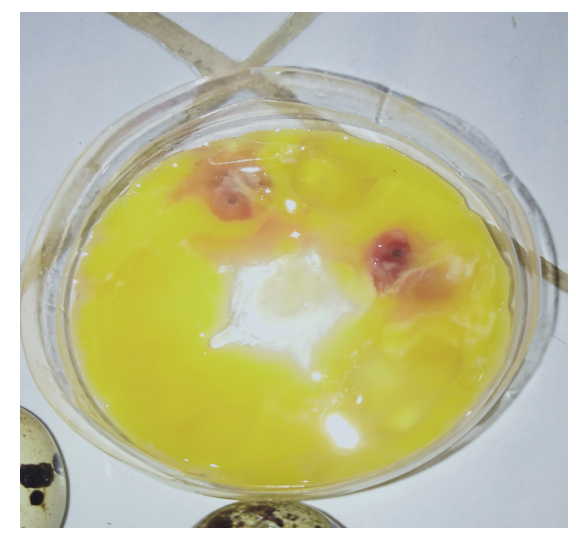

Gambar 1. Kematian Embrio Awal

Kematian embrio banyak terjadi pada mesin tetas suhu tinggi dengan indeks telur bulat karena suhu yang tinggi akan mempercepat metabolisme sehingga perkembangan embrio akan semakin cepat, tetapi dapat menghambat proses penetasan dan menyebabkan kematian ataupun abnormalitas embrio. Suhu dianggap sebagai faktor penting mempengaruhi perkembangan embrio, daya tetas, dan performa setelah menetas (Lourens et al., 2005). Menembus kerabang, dan kematian setelah beberapa saat setelah menetas (Gambar 2).

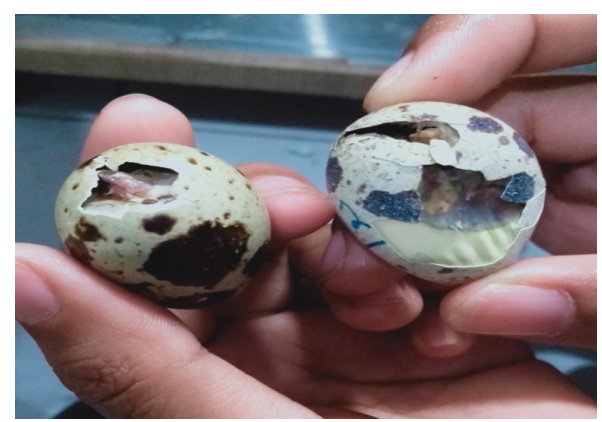

Gambar 2. Kematian Embrio Akhir

Pengaruh suhu terhadap kematian embrio tergantung pada masa inkubasi. Banyaknya embrio yang mati disebabkan pada tiga hari sebelum menetas merupakan masa-masa kritis bagi embrio. Embrio pada fase ini sangat rentan terhadap perubahan lingkungan inkubator dan banyak terjadi karena aktivitas metabolismenya rendah di dalam telur (Yildirim and Yetisi, 2004). Dari telur yang diamati dan dipecahkan banyaknya embrio yang mati pada fase akhir umumnya karena kegagalan pipping.

Menurut Nakage et al. (2003) bahwa kematian embrio tengah dan akhir penetasan disebabkan suhu yang tinggi. Kematian embrio yang tinggi di akhir penetasan juga disebabkan oleh kegagalan dalam transisi respirasi allantoic ke paru-paru. Pembuluh darah allantoic bertanggung jawab untuk respirasi dan ekskresi, tetapi embrio gagal ketika embrio memecahkan membran cangkang menggunakan paruh untuk mengakses ruang udara 
maka embrio akan mati (Peñuela and Hernandez, 2018).

Pengaruh indeks bentuk telur, hasil penelitian yang sama dilaporkan oleh Alasahan dan Copur (2016) bahwa bentuk telur tidak mempengaruhi $(\mathrm{P}>0.05) \quad$ KEAh. Walaupun tidak berbeda, bentuk L mempunyai KEAh hampir sama dengan telur bentuk $\mathrm{B}$ $(6,73 \%$ dan 6,62\%). Tidak terdapat interaksi antara faktor suhu dan indeks bentuk telur $(\mathrm{P}>0,05)$ terhadap KET. Berbeda dengan KEA, penelitian ini menunjukkan bahwa suhu tinggi dan bentuk lonjong (TL) menghasilkan KET yang tertinggi $(14,4 \%)$ dan yang terendah pada suhu tinggi dan bentuk telur bulat (RB) $(5,7 \%)$.

Secara umum, kematian embrio selama proses pengeraman dapat terjadi karena pengaruh nutrisi yang terkandung dalam telur dan posisi embrio yang tidak menguntungkan. Menurut North (1978), saat inkubasi berlangsung posisi kuning telur dapat naik dan menempel pada bagian luar selaput putih telur. Menurut Tona et al., 2001 bahwa kematian embrio paling rentan terjadi pada empat hari pertama dan tiga hari terakhir. Persentase mortalitas tertinggi terjadi pada awal dan akhir inkubasi pada saat penetasan.

\section{Daya tetas dan kualitas tetas}

Suhu dan indeks bentuk telur tidak berpengaruh $(\mathrm{P}>0,05)$ terhadap daya tetas telur fertil (Tabel 1). Suhu rendah menghasilkan rata-rata daya tetas 16,2 persen lebih tinggi dari pada ditetaskan pada suhu tinggi $(66,1 \%$ vs $49,9 \%)$. Indek telur bulat menghasilkan rata-rata daya tetas yang lebih tinggi dari pada indeks telur bentuk lonjong (59,3\% vs $56,7 \%)$.

Interaksi suhu dan bentuk telur juga tidak mempengaruhi daya tetas telur fertil $(\mathrm{P}>0,05)$. Akan tetapi suhu rendah dan bentuk telur bulat maupun lonjong menghasilkan daya tetas yang lebih tinggi dari pada ditetaskan pada suhu tinggi.

Dengan kata lain, menetaskan telur puyuh pada suhu rendah $\left(37^{\circ} \mathrm{C}\right)$ lebih baik dari pada suhu tinggi $\left(39^{\circ} \mathrm{C}\right)$. Kehilangan air pada telur berkorelasi terhadap suhu inkubator (Peñuela and Hernandez, 2018). Selama awal perkembangan embrio, suhu embrio lebih rendah daripada suhu inkubator karena pendinginan evaporatif. Nowaczewski et al. (2013) melaporkan bahwa telur puyuh mengalami peningkatan suhu kulit telur antara hari ke 2 sampai 12 inkubasi, dan terjadi penurunan pada hari ke-14 inkubasi. Hasil penelitian ini sesuai dengan hasil penelitian Alasahan and Copur (2016) bahwa daya tetas telur dari telur fertil tidak dipengaruhi oleh indeks bentuk telur walaupun daya tetas penelitian ini lebih rendah dari yang dilaporkan kedua peneliti tersebut. Berbeda dengan Maclatjry et al. (1973) bahwa analisis regresi data dari 2.815 telur puyuh fertil menunjukkan regresi linier yang sangat 
signifikan antara daya tetas dan indeks bentuk telur.

Kualitas tetas tidak dipengaruhi oleh suhu dan bentuk telur $(\mathrm{P}>0.05)$. Penelitian ini juga dilaporkan oleh Yildirim and Yetisir (2004) bahwa suhu tidak mempengaruhi kondisi phisik embrio dan suhu yang sangat kritis pada 5 hari terakhir pada ayam. Suhu tinggi penyebab kematian akan tetapi suhu rendah memperpanjang waktu menetas karena menetas kondisi normal tergantung pada level kehilangan air.

Suhu dan indeks bentuk tidak berpengaruh $(\mathrm{P}>0,05)$ terhadap daya tetas dari total telur. Suhu rendah menghasilkan daya tetas 15,0 persen lebih tinggi dari pada ditetaskan pada suhu tinggi (56,3\% vs 41,3\%). Indek telur bulat menghasilkan daya tetas yang lebih tinggi dari pada indeks telur bentuk lonjong $(52,1 \quad \%$ vs $45,6 \%)$. Hasil penelitian ini sesuai dengan hasil penelitian Alasahan dan Copur (2016) bahwa daya tetas telur dari fertil tidak dipengaruhi oleh bentuk telur walaupun daya tetas penelitian ini lebih rendah.

\section{SIMPULAN DAN SARAN}

Perbedaan suhu inkubator dan indeks bentuk telur tidak berpengaruh terhadap kematian embrio, daya tetas dan kualitas tetas. Namun demikian penelitian ini menyarankan menetaskan telur puyuh lebih baik menggunakan mesin tetas suhu rendah $\left(37^{\circ} \mathrm{C}\right)$ dan telur berbentuk bulat.

\section{DAFTAR PUSTAKA}

Alasahan SI and AG Copur. 2016. Hatching characteristics and growth performance of eggs with different egg shapes. Brazilian Journal of Poultry Science., 18 (1): 001-008 http://dx.doi.org/10.1590/1516635x1801001-008.

Aryee, G., G. Adu-Aboagye, ME. Shiburah, T. Nkrumah, and D. Amedorme. 2020 Correlation between egg weight and egg characteristics in Japanese quail. International Journal of Animal Science and Technology. 8 (3) 51-54. doi: 10.11648/j.avs.20200803.11

Elsayed, N.A.M, Allan E.E., Amina S.E., and E. Y. Hassan. 2009. New suggested schemes for incubation temperature and their effect on embryonic development and hatchability. Poultry Science, 3(1): 19-29.

Givisiez PEN, Bruno LDG, Machado JRSA, Secato ER, Freitas D, Ribeiro LT, Macari M. Desempenho e resposta ao estresse calórico gradativo de frangos submetidos a estresse de calor e frio durante a incubação. Revista Brasileira de Ciência Avícola (Suplemento) . 2000. 2:1 (Performance and response to gradual heat stress in broilers subjected to heat and cold stress during incubation Brazilian Journal of Poultry Science).

Kul, S, and L. Seker. 2005. Phenotype correlation between some external and internal egg quality traits in the Japanese quail (Coturnix coturmix japonica). International Journal of Poultry Science. 3 (6): 400-405 
Lourens, A., H. Van den Brand, R. Meijerhof, and B. Kemp. 2005. Effect of eggshell temperature during incubation on embryo development, hatchability, and post hatch development. Poultry Science 84:914-920.

Maclatjry, DW., WM. Insko, JR., JJ. Begin and TH. Johnson. 1973. Shape index versus hatchability of fertile eggs of Japanese quail (Coturnix coturnix japonica). Poultry Science, 52: 558-562.

Meijerhof, R. 2009. The influence of incubation on chick quality and broiler performance. Pages 167170 in $20^{\text {th }}$ Annual Australian Poultry Science Symposium. Sydney. Australia.

Nakage, E.S., J.P Cardozo, G.T. S.A Pereira and I.C Boleli. 2003. Effect of temperature on incubation period, embryonic mortality, hatch rate, egg water loss and partridge chick weight (Rhynchotus rufescens). Brazilian Journal of Poultry. Science. 5 (2): 131-135. https://doi.org/10.1590/S1516635X2003000200007

North, N. O. and Donald D. Bell. 1978. Commercial Chicken Production Manual. 2 nd Edition. Avi Publishing Co. Inc, Connecticut

Nowaczewski, S., T. Szablewski, R. Cegielska-Radziejewska, and $\mathrm{H}$. Kontecka. 2013. Microbiological response of Japanese quail eggs to disinfection and location in the setter during incubation. Folio Biologica (Krakow), 61(1-2): 119-124

https://europepmc.org/article/me $\mathrm{d} / 23767303$
Parkhurst, C.R. and G.J. Mountney. 1988. Poultry Meat and Egg Production. Van Nostrand Reinhold Co. New York

Peñuela A and A Hernandez. 2018. Characterization of embryonic mortality in broilers. Revista MVZ Córdoba 23(1):6500-6513

Romao, J.M., T.G.V. deMoraes,., R Teixeira, and W.M. Cardoso. 2009a. Incubation of Japanese quail eggs at different temperatures: Hatchability, hatch weight, hatch time and embryonic mortality. Archives of Veterinary Science, 14 (3): 155-162

Romao J. M, T.G.V Moraes, R.S.C Teixeira, C Buxade C and W.M Cardoso. 2009b: Effect of relative humidity on incubation of Japanese quail eggs. Livestock Research for Rural Development. Volume 21, Article \#38. Retrieved April 3, 2021, from http://www.lrrd.org/lrrd21/3/ro ma21038.htm

SAS Institute. 2004. SAS User's Guide: Statistics. Version 9.1. SAS Institute, Inc., Cary, NC;

Soliman, F.N.K., R.E. Rizk and J. Brake. 1994. Relationship between shell porosity, shell thickness, egg weight loss, and embryonic development in Japanese quail eggs. Poultry Science, 73 :1607-1611. 
Tona, K. F. Bamelis., W. Coucke., V. Bruggeman and E. Decuypere. 2001. Relationship between broiler breeder's age and egg weight loss and embryonic mortality during incubation in large scale conditions. Journal of Applied Poultry Research 10(3): 221-227.
Visschedijk, A. H. J. 1991. Physic and Physiology of incubation. British Poultry Science. 23: 3-20.

Yildirim, I. and R. Yetisir. 2004. Effects of different hatcher temperatures on hatching traits of broiler embryos during the last five days of incubation. South African Journal of Animal Science 2004, 34 (4):211-216 